\title{
Ficciones televisivas argentinas en los festivales internacionales de cine
}

\author{
Argentine TV Fictions at International Film Festivals
}

\section{Carolina Soria}

Universidad de Buenos Aires, Buenos Aires, Argentina

soriacarolinågmail.com

\section{Resumen}

Este artículo examina la reciente participación de series de ficción argentinas en los festivales internacionales de cine en un contexto audiovisual dominado por cambios radicales en la producción, distribución y consumo. La propuesta de este trabajo es describir la identidad múltiple del audiovisual contemporáneo y postular que la incursión de artistas reconocidos en el formato televisivo -y su exhibición en los festivales - funciona como una doble operación legitimante, elevando a la serie como producto cultural y expresión artística. Desde esa perspectiva se analizará la construcción narrativa y estilística de dos ficciones argentinas como también los recorridos emprendidos por ellas -su emisión televisiva, en plataformas en línea y en festivales audiovisuales-. Las conclusiones del artículo apuntan a destacar el lugar central que ocupan la circulación y distribución de la ficción televisiva en la industria audiovisual y en los espacios de reconocimiento tradicionalmente asociados al cine y la televisión.

Palabras clave: series televisivas de ficción, cineastas argentinos, festivales internacionales de cine, distribución, consumo.

\begin{abstract}
This article examines the recent participation of Argentinian television series in international film festivals in an audiovisual context dominated by radical changes in production, distribution and consumption. The proposal of this work is to describe the multiple identity of contemporary audiovisual and postulate that the incursion of recognized artists in the television format -and its exhibition at film festivals - works as a legitimate double operation, elevating the series as a cultural product and artistic expression. From this perspective, the narrative and stylistic construction of two Argentine fictions will be analyzed, as well as the journeys undertaken by them -their television broadcast, online platforms and audiovisual festivals-. The conclusions of the article aim to highlight the central place occupied by the circulation and distribution of television fiction in the audiovisual industry and in the recognition spaces usually associated with film and television.
\end{abstract}

Keywords: argentine TV series fiction, filmmakers, international film festivals, distribution, consumption. 


\section{Introducción}

Dentro de un amplio repertorio de series de ficción que comienzan a realizarse en la Argentina hacia el 2010 y en los años subsiguientes, destacan especialmente tanto las peculiaridades narrativas y estilísticas como los itinerarios emprendidos por dos de ellas: La casa (2015), dirigida por Diego Lerman; y Cromo (2015), dirigida por Lucía Puenzo, Nicolás Puenzo y Pablo Fendrik. Ambas tienen en común ser ficciones televisivas realizadas por cineastas argentinos, haber sido ganadoras de los concursos de fomento promovidos por el Estado y - además de emitirse por la Televisión Públicahaber sido seleccionadas para participar en festivales internacionales de cine, inaugurando secciones de exhibición exclusivas dedicadas a series de televisión. Esto último constituye el eje articulador de este trabajo, el cual apunta a examinar a partir del caso argentino, la creciente participación del producto serial en espacios de exhibición tradicionales como los festivales de cine y la necesidad de reflexionar, en primer lugar, sobre las nuevas formas de producción, distribución y exhibición de la narrativa seriada; y en segundo lugar, sobre el lugar que ocupa dentro de la industria audiovisual contemporánea.

El entramado conceptual que proponemos pone el acento en el rol de los festivales de cine como espacios de negociación e instancias de legitimación de los productos culturales que en ellos se exhiben. Se trata de una fundamentación que permite adentrarnos y describir este nuevo escenario caracterizado por la multiplicidad de identidades que envuelve a cada medio, los cuales ofrecen una variedad de formas de consumo. Dentro de este marco de referencia nos centraremos en las series argentinas de Diego Lerman, los hermanos Puenzo (Lucía y Nicolás) y Pablo Fendrik para analizar, de manera conjunta, la construcción de su dimensión narrativa y las diferentes formas y espacios de exhibición.

\section{Marco Teórico}

La serie de ficción se ha convertido en los últimos años en una forma narrativa audiovisual contem- poránea de gran consumo y su diseminación a escala global es innegable (Broe, 2019; Cascajosa, 2016). Se trata de un fenómeno cultural en el que las plataformas digitales ocupan un lugar central para su visualización al tiempo que se promueve la creación de nuevos espacios. Este panorama audiovisual impregnado por las narrativas seriadas ha modificado y complejizado cada una de las instancias de la producción, la exhibición y el consumo al tiempo que el formato se ha convertido en un objeto de estudio vivo capaz de generar nuevas conceptualizaciones a medida que se desarrolla (Gauthier, 2018; Pousa, 2018; Zafra, 2017; Scolari, $2013,2008)$. La exhibición de estas ficciones audiovisuales ya no se limita al ámbito de la televisión sino que su visionado abarca las plataformas de internet e incluso, como veremos en este trabajo, los festivales de cine. Estas formas de circulación nos enfrentan "ante un modelo de negocio que amplía el recorrido tradicional de la emisión convirtiendo a la distribución en una pieza clave de la internacionalización del producto, que condiciona no solo las estrategias de compra, sino también las de producción" (Pousa, 2018, p.18).

En las últimas décadas los festivales se han erigido como agentes fundamentales en el fomento de la producción, distribución y exhibición del audiovisual contemporáneo, se han convertido en espacios de intercambio transnacional (Peirano, 2018) y los estudios académicos en torno a ellos crecieron exponencialmente dando lugar a nociones que permiten comprender el audiovisual, en general, en su dimensión globalizada. Los productos son concebidos para ser lanzados al mercado internacional con el objetivo de participar de concursos que premian con la financiación de instancias de producción o posproducción como también para emprender el recorrido pautado por las diferentes ventanas de exhibición posibles (mercados y festivales audiovisuales).

Un fenómeno aún más reciente y que se desarrolla en paralelo al incremento del consumo de series de ficción, es la creación de secciones especiales dentro de los festivales internacionales de cine para su exhibición exclusiva. Estos eventos se adaptan al actual mercado audiovisual y se hacen eco de las nuevas formas discursivas y de consumo, ofreciendo un espacio dentro del cual las series se enfrentan a posibilidades de producción, distribución y exhibición alternativas la la de su transmi- 
sión televisiva tradicional o a la visualización en las plataformas de internet). Por otro lado y, además de constituir un espacio de marketing para la promoción de películas, los festivales funcionan como agentes legitimantes de las producciones que en ellos se exhiben: los premios y elogios de la crítica que reciben los films auguran su lanzamiento al mercado internacional y prometen tanto el reconocimiento de sus directores como el afianzamiento de sus carreras (Chan, 2001). Se trata, en los términos planteados por Rodríguez Isaza (2014) de una estrategia estandarizada para elevar el estatus artístico y cultural de productos cinematográficos dirigidos al mercado internacional. La gran cantidad de este tipo de eventos permite establecer un paralelo con la noción de bienalización del arte que plantea Andrea Giunta para referirse a la multiplicación de encuentros artísticos realizados en diferentes ciudades. En este sentido, las bienales, al igual que los festivales de cine, resultan ser espacios en los cuales tienen lugar convenios, negocios e intercambios de representaciones de la producción artística internacional (2007). Como señalan Cerdán y Fernández Labayen (2017), la televisión aceleró y popularizó el proceso de trasnacionalización que el cine había iniciado, especialmente en círculos exclusivos y de élite.

Si bien aún no hay estudios específicos que indaguen en profundidad sobre la circulación de las series televisivas en los festivales de cine, en los últimos años se elaboraron conceptos que arrojan luz sobre el presente contexto audiovisual de los medios digitales. Un contexto en el que domina la fragmentación de audiencias y la diversificación del consumo cultural junto a los cambios tecnológicos, sociológicos y regulatorios que transformaron el modelo tradicional de televisión. Nociones como hipertelevisión (Scolari, 2013), televisión mutante (Zafra, 2017) y ficciones convergentes (Pousa, 2018), describen este panorama y resultan imprescindibles para abordar nuestro objeto de estudio, al tiempo que apuntan a visibilizar la identidad múltiple del audiovisual contemporáneo. Sobre esta cuestión y al reflexionar sobre la televisión dentro de la historia de los medios, es productivo el modelo de crisis que propone Rick Altman (1996) al analizar el cine como una historia discontinua de fenómenos múltiples, y las tres etapas que se superponen y repiten en toda crisis: identidad múltiple lpor la introducción de una nueva tecnología, una nueva práctica social o una nueva forma de explotación); lucha jurisdiccional (campo de batalla por el control del uso y la práctica de la nueva tecnología); acuerdo negociado ( nuevas alianzas entre los sistemas de representación y quienes los fabrican, distribuyen y consumen).

Esta noción de identidad múltiple resulta eficaz para describir la narrativa audiovisual televisiva y encuentra su fundamento también en algunos de los rasgos con que Scolari (2008) define a la hipertelevisión, como la confusión entre los géneros y el borramiento de sus límites, las narraciones transmediáticas (Jenkins, 2008) consistentes en la expansión de las historias a través de diferentes medios, y la participación activa y colaborativa de la audiencia. De la misma manera, la naturaleza creativa por parte del espectador también ha llevado a la creación de terminologías compuestas que dan cuenta de la complejidad y multiplicidad. Tal es el caso del término "interactor" (interacción+actor) propuesto por Gauthier (2018) que reemplaza al tradicional "espectador" o "televidente" y permite describir la experiencia estética producida por las narrativas transmedias.

Dentro de este nuevo paradigma en el que se difuminan los límites entre los medios de expresión y los modos de consumo, la convergencia mediática (Jenkins, 2008) se erige como estandarte del dinamismo que caracteriza el presente audiovisual dominado por la circulación de contenidos a través de múltiples plataformas y el consecuente desplazamiento de las audiencias. En este contexto resulta productiva la noción de "ficciones convergentes" propuesto por Pousa, una categoría que existe de una manera genérica desde el nacimiento de la propia televisión, por la vinculación de sus relatos audiovisuales de ficción con los folletines del siglo XIX mediante la serialidad, por la práctica del teatro filmado y su dramaturgia o por la tecnología, el lenguaje y el ritmo cinematográficos (Pousa, 2018, p. 25).

Se trata de un concepto que describe la intermedialidad intrínseca a la televisión, la convivencia de diferentes modos de representación que también caracterizó al cine desde sus comienzos por sus deudas con otras series culturales como el teatro, el circo, el ballet y los números de magia. La nueva forma de expresión que emergía a principios del siglo XX -al igual que en los primeros años de la historia de la televisión en la Argentina-, también 
se enriqueció con el prestigio de actores, actrices y guionistas provenientes del teatro y la literatura, y pudo así incorporarse al campo cultural tradicional y conquistar a un público culto.

Por último, y previo a adentrarnos en las particularidades de la narrativa seriada argentina, resulta paradójico que la participación del medio televisivo en los festivales reivindica la experiencia colectiva cinematográfica del visionado en sala, desplazando la situación individual que caracteriza la fragmentación del consumo televisivo en general y de la narrativa seriada en particular.

\section{Las series de ficción en Argentina}

Inmersa dentro de un proceso histórico de transformación de las producciones de ficción en América Latina, hacia el año 2010 la Televisión Pública argentina exhibe una renovación inédita en la oferta de formatos y contenidos narrativos de su programación. En ella sobresale el desarrollo de la narrativa seriada ficcional que surgió, principalmente, como resultado de concursos de fomento estatales organizados por el Instituto Nacional de Cine y Artes Audiovisuales (INCAA) y el Ministerio de Planificación, Inversión Pública y Servicios. Prácticamente en simultáneo a su estreno dentro de la grilla televisiva tradicional y su lanzamiento en plataformas de internet, estas series comenzaron a participar en las nuevas secciones de los festivales internacionales de cine como también en aquellos exclusivos para series web y televisión.

Un gran número de estas ficciones televisivas fueron realizadas por cineastas y dramaturgos en un contexto de cambios legislativos, tecnológicos e institucionales ${ }^{1}$, y entre ellas fueron seleccionadas para formar parte de la programación de festivales: La casa (2015), dirigida por Diego Lerman; y Cromo (2015), dirigida por Lucía Puenzo, Nicolás Puenzo y Pablo Fendrik. La ficción de Lerman, reconocido realizador cinematográfico de films como Tan de repente (2002), Mientras tanto (2006) y La mirada invisible (2010) (entre otros) tuvo su estreno internacional en el Festival de Cine de Rotterdam en la sección destinada a series televisivas internacionales creadas por cineastas y denominada Episodic-Epidemic; Cromo fue el único producto te- levisivo de América Latina seleccionado para participar en la nueva sección Primetime del Festival Internacional de Cine de Toronto.

A continuación se indaga en estas series y sus recorridos para reflexionar sobre las nuevas formas de producción, distribución y consumo de la narrativa seriada de ficción y los criterios estéticos tenidos en consideración para la selección de los proyectos, los cuales se relacionan con la cada vez más difusa frontera entre televisión y cine que señalan directores, críticos y organizadores de festivales. Postulo que tanto la incursión de los artistas (directores, actores, actrices y guionistas) en esta forma narrativa y la exhibición de la misma en los festivales de cine funciona como una doble operación legitimante de la serie televisiva como producto cultural y expresión artística. Coincidimos con Pousa en que "el concepto autoral, unido al imperante marketing de las plataformas, determina la presencia de las producciones televisivas en estos festivales" (2018, p. 29), las cuales a su vez permiten que los festivales se legitimen a sí mismos incorporando en su programación a figuras de renombre.

\subsection{La casa}

La ficción de Diego Lerman fue producida por Campo Cine y tras su emisión en la Televisión Pública en marzo del 2015 emprendió un recorrido por diferentes festivales y mercados. Su primera participación internacional fue en el mismo año en el Festival Series Manías que tuvo lugar en el Forum des Images de Paris y luego en el Festival de Cannes (Marche du Films). En el 2016 fue la primera serie que representó a Latinoamérica en la programación del Festival de Cine de Rotterdam en su nueva sección destinada a series de ficción televisiva". Allí se exhibieron cuatro episodios ("Secuestro", "Revolucionarios", “Ficción” y “Virus") y fue presentada en la página web del festival como una "rareza audaz" dentro de la televisión argentina en materia de series. Según el realizador, La Casa por su propuesta narrativa y su forma de producción, constituye una novedad y el espacio del Festival de Rotterdam ofrece una gran oportunidad para mostrar productos diferentes de la televisión tradicional (Van Vliet, 2016).

La ficción recorre la historia argentina a través de las décadas a lo largo de trece episodios, en los 
cuales diferentes narraciones autoconclusivas tienen en común el espacio que habitan, un caserón ubicado en el Delta del Tigre. Cada historia, además de recurrir a géneros y estilos cinematográficos acorde con el periodo en el que tiene lugar, se ancla en el momento histórico y cultural del país dentro del cual se desarrolla. Según Lerman, los capítulos fueron pensados como pequeños mediometrajes (en Gallego, 2015) y abordados desde diferentes géneros de la historia del cine, utilizando cada época como una excusa formal para abordar los diferentes lenguajes cinematográficos. Por ejemplo, el primer capítulo titulado "Criatura", situado en 1929, se filmó en blanco y negro, el estilo del guión se asemeja a la literatura de Edgar Allan Poe y la estética tiene una impronta entre gótica y expresionista. En cambio el siguiente episodio ("Despedida"), cuyos protagonistas encarnan a Carlos Gardel y Alfredo Le Pera días antes del trágico accidente aéreo, se sitúa en 1935 y remite al cine tanguero de la Argentina de la década del treinta. Y así, la ficción televisiva revisita tanto los diferentes periodos de la historia y de la cultura argentina - la muerte de Eva Perón el 26 de julio de 1952, el mundial de fútbol de 1978 en plena dictadura militar, los levantamientos militares a los gobiernos democráticos de Raúl Alfonsín y Carlos Saúl Menem por parte de los denominados "carapintadas"-, como de los diferentes estilos cinematográficos, entre ellos el cine de Hollywood de los cuarenta, el western de los cincuenta y la nouvelle vague de los sesenta.

Cada capítulo de La casa comienza con el relato de una voz en off que presenta a los personajes y su pasado inmediato, explica el devenir de la vivienda y las historias que envuelven a sus habitantes. La narración oral que se adelanta al título y a los créditos iniciales, es acompañada por la yuxtaposición de imágenes de archivo de carácter tanto documental como ficcional en sus diferentes materialidades: fotografías, periódicos y videos. El último episodio, uno de los cuatro que pudo verse en el Festival de Rotterdam y que se titula "Virus", construye su material narrativo en un futuro distópico (año 1929) en el cual un virus acecha a la población mundial. Sorprendentemente ese futuro no es tan diferente al presente de este artículo, inmerso en los avatares de la pandemia de COVID-19. La voz introductoria nos sitúa en el verano del 2021, en los días en que Sofia (Erica Rivas) organiza una fiesta en el caserón para celebrar su cumpleaños núme- ro veintiuno. Las imágenes se suceden mediante un montaje vertiginoso, amalgamando fotografías que ilustran aquello que relata la voz en off o que completan su representación en la banda sonora. Por ejemplo se filtran auditivamente la música electrónica de la fiesta y la sirena de una patrulla de policía. Esta apertura narrativa finalmente nos ubica en el año 2025, cuando el padre de Sofía enferma y ella se dedica a cuidarlo durante los dos años siguientes. Como promete la voz narradora “serán años penosos que conducirán a una lenta pero segura decadencia de la casa".

Finalizado el prólogo y tras la presentación del título que da nombre a la serie, el punto cero del relato nos introduce en el año 2029, en el exacto momento en que Sofía y su pareja llegan a la casa del Tigre cubiertos de máscaras en sus rostros. Ella está embarazada y la vivienda familiar que se encuentra desocupada y en estado de abandono representa un refugio seguro lejos de la ciudad. Las últimas noticias periodísticas que la protagonista recibe comunican cifras y datos devastadores, como la instalación de hospitales de campaña, la cuarentena obligatoria, toques de queda en varias ciudades y el cierre de los pasos fronterizos. La desolación y preocupación invaden el estado de ánimo de Sofía como también los espacios que ocupa. La iluminación tiñe las habitaciones de tonalidades neutras y frías que oscilan en la gama de los grises y los verdes, colores que contribuyen a crear el clima distópico del episodio. Una vez instalada, la pareja advierte que el caserón no fue pensado como refugio únicamente por ellos. Primero llega su hermana (María Merlino) acompañada de su pareja (Carla Crespo) y luego su madre (Cristina Banegas). Evidentemente Sofía no mantiene relación con ninguna de las dos desde hace ya varios años y la convivencia no hace más que aflorar los reproches y acentuar los conflictos entre ellas. La paleta de colores y los primeros planos y planos medios fijos que prevalecen en los espacios interiores sin duda incrementan el clima de hostilidad y subrayan la tensión y deterioro de los vínculos entre las tres mujeres.

Como resultado de su paso por los festivales y mercados, la excelente repercusión internacional que tuvo la propuesta de Lerman hizo que la compañía francesa Loco Films adquiriese los derechos de la serie. También cosechó premios en la tercera edición de "Nuevas Miradas en la Televisión" 
(2015) otorgados por la Universidad de Quilmes en los rubros Mejor Ficción, Mejor Actriz (Erica Rivas) y Mejor Música (Gustavo Pomenarec) y fue nominada en el rubro Mejor Series y/o Telefilms de los Premios Cóndor de Plata (2016).

La incursión en la narración seriada significó para Lerman la posibilidad de experimentar con cine en la televisión (Van Vliet, 2016) y agenciar el rótulo de "cinematic serie" (Keslassy, 2015). Se trata nuevamente de una etiqueta que apunta a la identidad múltiple de la televisión de la misma manera que la noción de televisión "cinemática" propuesta por Mills (2013). Con este concepto se alude a aquellos programas que priorizan el aspecto visual en mayor proporción que la televisión habitual y en los cuales el desarrollo tecnológico permite una calidad de imagen y sonido superior e incluso un grado de manipulación mayor. El director de La casa remarcó que la serie fue filmada con una sola cámara, la puesta en escena tuvo una dedicación mayor que la destinada usualmente en televisión y que el "abordaje cinematográfico" propuesto llamó la atención de actores y actrices provenientes del mundo del cine, el teatro y la televisión para formar parte del experimento.

Con respecto al lugar conferido dentro del Festival de Cine de Rotterdam, el director artístico Bero Beyer junto al programador Léo Soesanto crearon la sección Episodic - Epidemic ${ }^{3}$ para celebrar todas las modalidades en que los cineastas se expresan y encontrar así la mejor manera de presentar diferentes tipos de narración (Pritchard, 2016) 4 . En el catálogo del festival y dentro de la presentación de esta sección, Soesanto explica su nombre, el cual proviene de la idea: "La serie televisiva se ha convertido en una fuerza cultural que se ha propagado como un virus, afectando conversaciones cotidianas, adentrándose en la mente de realizadores cinematográficos que trabajan para la televisión y en las programaciones de los festivales de cine que las proyectan (Toronto, Berlin, Sundance)" $(2016, \text { p. 206) })^{5}$. Asimismo, programadores se hacen eco de los cuestionamientos frecuentados por el creciente consumo de la serie de televisión -"Películas versus series. ¿Es el cine mejor que la televisión? ¿Es la televisión el nuevo cine?" (2016, p. 206) - y enfatiza que la sección no toma partido. El responsable de la programación señala que el nombre "episodic" fue elegido para identificar el núcleo de contar historias en episodios, los cuales permiten experimentar con el tiempo y el ritmo. Justamente dentro de las modalidades de esta nueva sección (documental, formato largo, binge-watchingl la serie de Lerman fue programada bajo el lema de experimental, enfatizando en la descripción presentada en el catálogo el abordaje de diferentes géneros y estilos a través del tiempo. Se trata de una construcción ficcional portadora de una estructura narrativa compleja, uno de los rasgos distintivos de la hipertelevisión (Scolari, 2008).

\subsection{Cromo}

Un recorrido inverso tuvo la serie de los hermanos Puenzo y Fendrik, dado que unos meses antes de su emisión televisiva inauguró la nueva sección de Series Primetime del Festival Internacional de Cine de Toronto con la proyección de tres capítulos (de un total de doce): se mostraron los dos primeros y el octavo por su importancia para el desarrollo de la trama ${ }^{6}$. Escrita con el asesoramiento de investigadores de CONICET, la narración se centra en el esclarecimiento del crimen de una científica que investiga la contaminación producida por los desechos tóxicos de una curtiembre y los daños ocasionados al ecosistema de los Esteros del Iberá (Provincia de Corrientes) y a sus habitantes.

Instalada en el nordeste argentino, Valentina Riera (Emilia Attias) realiza una investigación de campo en las aguas del extenso humedal para determinar los niveles de cromo. Los resultados arrojarían cifras alarmantes y comprometedoras, tanto para el Director Ejecutivo de la empresa responsable (Daniel Veronese) como para la mayoría de los habitantes que viven de ella y no tienen más opción que ser cómplices a fin de conservar sus puestos de trabajo. La amenaza que representa el conocimiento público de las irregularidades de la curtiembre en el deshecho de los tóxicos motiva el crimen de la protagonista en el primer episodio. A partir de allí, se construye una narración a través de indicios que desentrañan todo aquello que rodea y encubre el atentado, apelando a varios de los tópicos frecuentados por el género policial: el triángulo amoroso, el asesino material/intelectual, el ocultamiento del arma homicida, un testigo que se encuentra bajo amenaza, un colega/amante que asume las funciones de detective y la corrupción policial. 
Un elemento invariable en las directrices del género y que forma parte del ordenamiento narrativo de la ficción es el flashback, procedimiento que estructura y organiza el recorrido por las diferentes pistas. Sin estar atado a una cronología de los hechos, la historia va y vuelve del pasado no solamente con el fin de esclarecer el crimen, sino también para conocer en detalle la vida profesional y personal de la protagonista. Además de constituir el punto neurálgico de los flashbacks, algunos indicios del pasado se materializan en el presente a través de diferentes dispositivos tecnológicos, como cámaras de seguridad, mensajes de audio y correos electrónicos. Como prueba del gran trabajo de producción, la serie no se circunscribe a los diferentes paisajes que exhiben los esteros correntinos ni a la Facultad de Ciencias Exactas y Naturales de la Universidad de Buenos Aires (Ciudad de Buenos Aires), sino que recorre también otros paisajes naturales como los de la Base Marambió (Antártida), el Parque Nacional Nahuel Huapi (Neuquén) y el Glaciar Perito Moreno (Santa Cruz). Estos lugares, a la vez que funcionan como escenarios de los diferentes nudos narrativos, ostentan su imponencia en las transiciones de las diferentes secuencias.

Lucía Puenzo contrastó su experiencia televisiva con su trabajo en el cine y le reconoció, como uno de sus beneficios, contar con un mayor tiempo destinado a la realización (doce semanas). Esta ventaja posibilitó la experimentación y la creación de numerosas subtramas, siendo los cierres de cada bloque el único componente televisivo (Gallego, 2015b).

Luego de la presentación de Cromo en el Festival Internacional de Cine de Toronto y tras el reconocimiento que obtuvo, sus derechos fueron adquiridos por la distribuidora francesa Pyramide International para adaptar la serie al largometraje. Su presidente, Eric Lagesse, manifestó la creciente porosidad entre el cine y la televisión (Goodfellow, 2015) además de reconocer una "calidad cinematográfica" en la ficción argentina. Lo mismo señaló Nicolás Puenzo al comparar la serie con una producción americana desde el punto de vista de la labor técnica (Lingenti, 2015). Mientras que la realizadora expresó:

Este sistema de producción, para nosotros que somos todos gente de cine, nos permitió pensar esta miniserie como una película de 12 horas, donde lo importante (...) no es lo que se cuenta sino cómo se cuenta, el ritmo, el tono, la música. Tuvimos toda la libertad del mundo (2015).

El periplo de la serie culmina con su adaptación al largometraje Cromo. La película de la serie y su estreno en la plataforma Contenidos Digitales Abiertos (CDA) el viernes 15 de enero del 2016 ${ }^{7}$. En claro contraste con la buena recepción que rodeó a la presentación de la ficción en el festival canadiense, su lanzamiento como largometraje no contó con la misma repercusión.

A diferencia de Diego Lerman, tras su paso por Cromo los directores volvieron a incursionar en el formato de la serie. En el caso de Lucía Puenzo y ante la parálisis que señala respecto de la situación del cine argentino en los últimos años (Gallego, 2018), emprendió diversos proyectos fuera de Argentina (dirigió en Chile la serie La jauría (2019) y en una entrevista menciona estar con un proyecto de Netflix en Colombia y otro en Estados Unidos). También Pablo Fendrik continuó por este camino, dirigió El jardín de bronce (2017) y está próximo a rodar la adaptación a miniserie de la novela policial argentina Entre hombres. Ante esta situación es preciso mencionar que el formato de la narrativa seriada se ha convertido últimamente en una fuente laboral tanto para directores como para actores y escritores argentinos. Ante la crisis cultural general y de la ficción televisiva en particular en la segunda mitad de la década, por la falta de políticas de Estado que protegen al sector, la escasez de producciones locales y la consecuente falta de trabajo e importación de ficciones extranjeras; la narrativa seriada estrenada en plataformas y en formato web atrae cada vez más a los profesionales del cine y el teatro. A la vez que ven en ellas una fuente de trabajo, reconocen aprovechar su incursión en el medio para explorar un nuevo lenguaje.

La sección Primetime del Festival de Cine de Toronto fue creada en el 2015 y, según el director artístico del festival, Cameron Bailey, el espacio se focaliza en la nueva edad dorada de la televisión que se caracteriza por una "programación global de alta calidad, excelente escritura y dirección que rivaliza con el mejor largometraje" (Hertz, 2018)8. El responsable del evento expresó a su vez que:

El cine y la televisión han estado convergiendo durante años, con muchos cineastas gravitando hacia la televisión para experimentar con ese 
medio. Primetime destacará estos desarrollos a nivel internacional, subrayando la creciente intersección entre estas dos culturas e industrias de la imagen en movimiento"(Powell, 2015)'.

Como podemos observar, los productos televisivos ingresan en estas secciones especiales -tanto del festival europeo como canadiense- de la mano de cineastas reconocidos, responsables de establecer el nexo entre los dos medios y garantes de ofrecer proyectos en los cuales pueda reconocerse esa “calidad cinematográfica" que mencionábamos recién. De esa manera, se presagia un vínculo fructífero entre los dos formatos a la vez que se asegura un caudal de público dispuesto a destinar un espacio dentro de la extensa agenda cinematográfica que caracteriza a los festivales para ver episodios de televisión. Con respecto a la audiencia de estas producciones, Bailey reconoció: "Nos dimos cuenta de que la audiencia de cine independiente es la misma que la que sigue esas series"(Hertz, 2018) ${ }^{\mathbf{1 0}}$.

\subsection{Unos límites cada vez más difusos}

La participación creciente de la televisión, como también de productos concebidos para plataformas en línea, y las colaboraciones que en dichos espacios toman forma, concretizan el establecimiento de aquello que Yúdice denomina redes culturales. Ellas se caracterizan, dentro de esta situación en particular, por ser sistemas de cooperación que vinculan procesos nuevos con otros más tradicionales a la vez que permiten "articular creadores de sectores cultos, tradicionales y de los nuevos medios (digitales, internet, etc)" (2003, p. 12). Esta incipiente convivencia entre los diferentes formatos exige de parte de los festivales tradicionales adecuarse a los nuevos paradigmas y dinámicas de producción y consumo cultural. Es así que, además de verse interpelados con la generación de nuevos espacios de exhibición dentro de la grilla cinéfila, estos eventos propician la creación de mercados especializados, premios y foros de debate y reflexión en torno a estos nuevos modos de producción audiovisual. En este sentido, la necesidad de adaptación de estos espacios tradicionales forma parte de un entorno de transformación (tecnológico, regulatorio, cultural) en el que los acuerdos y alianzas se encuentran en plena elaboración. La televisión mutante en los términos planteados por Zafra (2017) domina esta nueva era audiovisual de transformación perma- nente y es el resultado de este contexto de cambios. Dentro de este panorama inestable y supeditado a nuevas configuraciones resulta lógico encontrar que las formas narrativas y expresivas de los relatos seriados sean permeables a otros lenguajes artísticos, especialmente, que su territorio en constante expansión revele zonas de contacto con el cine.

Los criterios estéticos tenidos en consideración para la selección de los proyectos parecieran estar ligados al contorno cada vez más indefinido entre cine y televisión. En estudios previos se ha trabajado sobre la influencia del estilo visual cinematográfico en las series de televisión como garante de calidad (Cortés \& Rodríguez, 2011), poniendo especial atención en el análisis de los relatos seriados a los elementos expresivos provenientes del cine: composición y planificación de la puesta en escena, movilidad de la cámara y formato de grabación. Sin embargo, el auge de las series comenzó a generar en el ámbito de la crítica, realizadores y organizadores de festivales reflexiones acerca de la cada vez más delgada y difusa línea que separa a la televisión y el cine. Para Michael Lerman, programador de Primetime:

\section{La televisión cinematográfica ha proporcio- nado un nuevo carril para la experiencia del consumidor del arte cinematográfico (...) Estas series no solo superan los lími- tes de lo que se puede presentar, sino que también demuestran cómo se puede tras- cender la cultura, las artes visuales y las comunicaciones (Hertz, 2018)'11.}

Las argumentaciones que esbozan la permeabilidad entre ambos medios se centran en los desarrollos tecnológicos que ofrecen una mayor calidad de imagen y sonido priorizando el estilo visual, la presencia de directores, guionistas y técnicos prestigiosos del medio cinematográfico que se aventuran en el formato seriado, la complejidad narrativa y los altos presupuestos destinados para su producción. La convocatoria a actores y actrices consagrados en el cine como en el teatro nacional e internacional, confieren un prestigio adicional a las series generando mayores expectativas y garantizando calidad interpretativa.

Como señalamos al comienzo, la ficción televisiva serial constituye un nuevo referente cultural que emerge hacia el 2010 gracias a los avances tecno- 
lógicos, "unidos al interés por sofisticar los relatos audiovisuales mediante la ambición temática y un nuevo tipo de producción que imita la cinematográfica, al que algunos autores se refieren como calidad o televisión cinemática" (Pousa, 2018, p.19). Existen numerosos debates en torno a la calidad televisiva que suscita la narrativa seriada (Jenner, 2018; Bourdaa, 2011; Thompson, 2003). Las ficciones abordadas en este trabajo responden a varios de los criterios de los estudios académicos que reflexionan acerca de la misma. Especialmente, y como vimos más arriba, Cromo y La casa se destacan por las innovaciones estéticas que presentan, la relevancia de las temáticas que exploran y la presencia de directores, actores y actrices reconocidos en el campo cultural nacional. Estos elementos sin duda favorecen el recorrido internacional que emprenden los proyectos audiovisuales y que aseguraron el reconocimiento que tuvo cada uno de ellos tras su paso por los festivales.

\section{Conclusiones}

Al estar inmersos dentro de este proceso en desarrollo, las conclusiones no pueden ser más que provisorias y generadoras de nuevos interrogantes. A medida que se engrose el corpus de las series podremos indagar acerca de si los festivales, de la misma manera que funcionan como creadores de marcas de identidad en los films, favorecen el abordaje de determinadas temáticas y estilos narrativos. Cuestión que nos remite nuevamente a lo planteado por Giunta en relación con las bienales y la homogeneización del arte, la cual es expresada en la repetición de artistas y en una agenda de temas recurrentes. Asimismo, podremos examinar si la incursión en el formato de las series tiene una incidencia en las estéticas de producción cinematográfica de sus realizadores.

La expansión del audiovisual hacia la narrativa seriada junto a las nuevas y diversas formas de consumo, forman parte de un proceso cultural dentro del cual la circulación y la exhibición desempeñan un lugar central. Dentro del esquema de la distribución en los últimos años se multiplicaron los espacios destinados a la visualización de las series de ficción televisiva en donde producciones argentinas tuvieron la oportunidad de alcanzar nuevos merca- dos y recibir reconocimiento internacional. Además de Cromo y La casa, otras series nacionales formaron parte de la programación de los festivales, por ejemplo El aparecido (2011, Mariano Rosa) participó en el Festival de Cine de Almería (Andalucía, España). También series web como Los mentirosos (2019, Alejandro Jovic) y Noches de amor (2019, Pedro Levatil formaron parte de la selección oficial del Festival Canneseries 2019; y Gorda (2018, Tamy Hochman, Bárbara Cerro y Sol Rietti) fue convocada para participar en el Drama Series Days del Berlinale Series.

Por último, esta incursión progresiva de contenidos concebidos para la televisión y plataformas web dentro de las lógicas y dinámicas del circuito de festivales de cine sin duda refuerza a la narrativa seriada como producto cultural en la industria audiovisual. Como resultado de ello, también se crearon rubros especiales para este formato en las entregas de premios tanto cinematográficos como televisivos. La Casa y Cromo fueron nominadas en el 2016 en los Premios Cóndor de Plata otorgados por la Asociación de Cronistas Cinematográficos de la Argentina, inaugurando el nuevo rubro a Mejor Serie y/o Telefilme. De la misma manera, desde el 2018 se creó el Martín Fierro Digital dando lugar al reconocimiento de series de ficción web producidas, la mayoría de los casos, por universidades nacionales. En definitiva, podemos pensar en una dinámica doble: por un lado, la narrativa seriada explora formas de exhibición alternativas a la tradicional en la televisión; y, por otro, los festivales de cine no tardan en incorporar dicho producto cultural a su programación haciéndose eco de las nuevas formas de producción y consumo audiovisual.

\section{Notas}

1. En el plano legislativo, en el 2009 se sancionó la Ley de Servicios de Comunicación Audiovisual 26.522 (LCSA); en el plano tecnológico, hacia el 2010 se implementó la Televisión Digital Abierta (TDA) y, desde el punto de vista institucional, se crearon los concursos de fomento promovidos por el Instituto Nacional de Cine y Artes Audiovisuales (INCAA) y el Ministerio de Planificación Federal, Inversión Pública y Servicios. Estas transformaciones que describen la coyuntura que posibilitó el incremento de la oferta ficcional en la Televisión Pública fueron desarrolladas en profundidad por Soria (2018). 
2. Cabe mencionar que el director ya había participado en este festival con su film Tan de repente (2003) y el mediometraje La guerra de los gimnasios (2005).

3. Esta sección es una continuación del programa Changing Channels organizado en el 2013 por el Festival de Rotterdam. El objetivo de este espacio fue exhibir series realizadas por cineastas independientes para televisión y para la web.

4. Cita original: "Films versus series. Is the cinema better than TV? Is TV the new cinema?" (2016, p. 206).

5. Cita original: "Tv series have become such a cultural force that they spread like a virus -affecting our conversations, the mind of filmmakers working for televisión and the programmes of film festivals (Toronto, Berlin, Sundance)" (2016, p. 206).

6. Cromo también estuvo disponible para verse en Netflix y, al igual que La casa, en CDA (Contenidos Digitales Abiertos) y en Cont.ar.

7. Extraído de: http://emiliaattias-uruguay.blogspot. com/2016/01/cromo-la-pelicula-de-la-serie.html. Actualmente el largometraje está disponible en la plataforma Cont.ar y es presentado como un especial de dos horas, un resumen de la serie.

8. Cita original: "high-quality global programming, terrific writing, and direction that rivals the best feature filmmaking" (Hertz, 2018).

9. Cita original: "Film and television have been converging for years, with many filmmakers gravitating to television to experiment with that medium. Primetime will highlight these developments internationally, spotlighting the growing intersection between these two moving-image cultures and industries" (Powell, 2015).

10. Cita original: "We realized the audience for independent film is the same as those following those serial works" (Hertz, 2018).

11. Cita original: "Cinematic television has provided a new lane for the consumer's experience of cinematic art (...) These series not only push the boundaries of what can be presented, but also demonstrate how it can transcend culture, visual arts, and communications" (Hertz, 2018).

\section{Referencias}

Bourdaa, M. (2011). Quality Television: construction and de-construction of seriality. En: Pérez-Gómez, M.A. (Ed.) Previously on. Estudios interdisciplinarios sobre la ficción televisiva en la Tercera Edad de Oro de la Televisión, Sevilla: Biblioteca de la Facultad de Comunicación de la Universidad de Sevilla, 33-43.

Broe, D. (2019). Birth of the Binge: Serial TV and the End of Leisure. Detroit: Wayne State University Press.

Cascajosa, C. (2016) La cultura de las series. Barcelona: Laertes.

Cerdán, J. \& Labayen, M.F (2017). “Film and Television”. En: Lugo. M., López, A.M., Podalsky, L. (Eds.) The Routledge Companion to Latin American Cinema (pp. 344-357). Londres: Routledge.

Cortés, L. \& Rodríguez, M. M. (2011) La influencia del estilo visual cinematográfico en las series de ficción televisivas. En: Pérez-Gómez, M. A. (Ed.) Previously on. Estudios interdisciplinarios sobre la ficción televisiva en la Tercera Edad de Oro de la Televisión. Sevilla: Biblioteca de la Facultad de Comunicación de Sevilla, 71-87.

Chan, F. (2001). The international film festival and the making of a national cinema. Screen, 52 (2), 253-260.

Gallego, R. (26 de julio, 2018). Entrevista a Lucía Puenzo: “No recuerdo otro momento del cine con tal grado de parálisis". EscribiendoCine. Recuperado de http://www.escribiendocine.com/entrevista/0015057-lucia-puenzo-no-recuerdo-otro-momentodel-cine-con-tal-grado-de-paralisis/ 
Gallego, R. (27 de marzo, 2015). Entrevista a Diego Lerman: "Como director de cine me gustaba la posibilidad de la TV como gran laboratorio". EscribiendoCine. Recuperado de http://www.escribiendocine.com/entrevista/0010417-diego-lerman-como-director-de-cine-me-gustaba-la-posibilidad-de-la-tv-como-gran-laboratorio/

Gallego, R. (16 de septiembre, 2015). Entrevista a Lucía Puenzo: “Cromo fue de mucho aprendizaje y diversión para todos". EscribiendoCine. Recuperado de http://www.escribiendocine.com/entrevista/0011123-lucia-puenzo-cromo-fue-de-mucho-aprendizaje-y-diversion-para-todos/

Gauthier, P. (2018). Inmersión, redes sociales y narrativa transmedia: la modalidad de recepción inclusiva. Comunicación y medios, 37, 11-23. DOI: 10.5354/0719-1529.2018.46952

Giunta, A. (2007). La era del gran escenario. Revista Ñ, 19.

Goodfellow, M. (10 de septiembre, 2015). Pyramide acquires TV drama Cromo. Screendaily. Recuperado de https://www.screendaily.com/news/pyramide-acquires-tv-dramacromo/5092802.article

Hertz, B. (16 de agosto, 2018). TIFF 2018: Julia Roberts headlines festival's attempt to blur lines between film and televisión. The Globe and Mail. Recuperado de https://www. theglobeandmail.com/arts/film/article-tiff-2018-julia-roberts-headlines-festivalsattempt-to-blur-lines/

Jauregui, M., Puenzo, L. \& Puenzo, N. (Productores). (2015). Cromo. [Serie de televisión] Buenos Aires: Historias Cinematográficas.

Jenner, M. (2018). Netflix and the Re-invention of Television. Londres: Palgrave Macmillan.

Jenkins, H. (2008). Convergence culture. La cultura de la convergencia de los medios de comunicación. Barcelona: Paidós.

Kaminker, A. (Productor ejecutivo) \& Lerman, D. (Director). (2015). La casa. [Serie de televisión) Buenos Aires: Campo Cine.

Keslassy, E. (14 de mayo, 2015). Paris-Based Loco Films Launched, Sets Lerman's 'La Casa'. Variety. Recuperado de https://variety.com/2015/film/global/paris-based-locofilms-launched-sets-lermans-la-casa-exclusive-1201495840/

Larraín, P., Larraín, J.D., Poblete, A., Vesper, C. \& Goldschmied, R. (Productores ejecutivos). (2019). La jauría. [Serie de televisión]. Chile: Fábula, TVN, Fremantle, Kapow.

Lerman, D. (Director). (2002). Tan de repente [Película]. Argentina-Holanda: Lita Stantic Producciones / NYLON Cine.

Lerman, D. (Director). (2006). Mientras tanto [Película]. Argentina-Francia: BD Cine, Instituto Nacional de Cine y Artes Audiovisuales (INCAA), Pyramide Productions.

Lerman, D. (Director). (2010). La mirada invisible. [Película].Argentina-Francia-España: El Campo Cine S.R.L.

Lerman, D. (Director). (2015). La casa [Serie de televisión]. Buenos Aires: Campo Cine.

Lingenti, A. (5 de octubre, 2015). Cromo, una serie federal. La Nación. Recuperado de https:// www.lanacion.com.ar/espectaculos/cromo-una-serie-federal-nid1833685

Mills, B. (2013). "What does it mean to call television "cinematic'?". En Television Aesthetics and Style (pp.57-669). New York: Bloomsbury Academic.

Peirano, M. P. (2018). Festivales de cine y procesos de internacionalización del cine chileno reciente. Cuadernos.Info, 43, 57-69. DOI: 10.7764/cdi.43.1485

Pousa, L. (2019). Las plataformas y la creación de contenidos mainstream: una aproximación a las nuevas «ficciones convergentes». Secuencias, 47, 5-32. 
Powell, A. W. (15 de mayo, 2015). Toronto International Film Festival going Primetime with television programme. The Gate. Entertainment Magazine. Recuperado de https:// www.thegate.ca/spotlight/tiff/023195/toronto-international-film-festival-goingprimetime-with-television-programme/

Pritchard, T. (31 de enero, 2016). Rotterdam fest tunes back into TV. Screendaily. Recuperado de https://www.screendaily.com/rotterdam/rotterdam-fest-tunes-back-intotv/5099614.article

Rosa, M. (Director). (2011). El aparecido. [Serie de televisión]. Salta: CHULO Productora Audiovisual.

Rodríguez Isaza, L. (2014). De «gira» por los festivales: patrones migratorios del cine latinoamericano. Secuencias, 39, 65-82.

Scolari, C. (15 de junio, 2013). La tv después del broadcasting: hipertelevisión, redes y nuevas audiencias. Hipermediaciones. Recuperado de https://hipermediaciones. com/2013/06/15/la-tv-despues-del-broadcasting-hipertelevision-redes-y-nuevasaudiencias/

Scolari, C. (2008). Hacia la hipertelevisión. Los primeros síntomas de una nueva configuración del dispositivo televisivo. Diálogos de la Comunicación, 77, julio-diciembre, 1-9. Recuperado de file://Users/carolinasoria/Downloads/Dialnet-HaciaLaHipertelevision-2694422\%20(4).pdf

Soesanto, L. (2016). Catalogue International 45th Film Festival Rotterdam. Recuperado de https://issuu.com/iffr/docs/catalogue_iffr_2016_lr

Soria, C. (2018) Dramaturgos y cineastas en la televisión: nuevas series ficcionales en la Argentina. Revista Iberoamericana 69 (18), septiembre-diciembre, 207-223. DOI: http://dx.doi.org/10.18441/ibam.18.2018.69

Suar, A. \& Andrasnik, D. (Productores ejecutivos). (2017). El jardín de bronce [Serie de televisión]. Argentina-Estados Unidos: Pol-Ka Producciones, HBO.

Thompson, K. (2003). Storytelling in Film and Televisión. Cambridge: Harvard University Press.

Van Vliet, A. (4 de febrero, 2016). Filmmakers on televisión. https://iffr.com/en/blog/filmmakers-on-television

Yudice, G. (mayo, 2003). Sistemas y redes culturales: ¿cómo y para qué? Trabajo presentado en el Simposio Internacional: “Políticas culturales urbanas: Experiencias europeas y americanas", Bogotá.

Zafra, J. M. (2017). La televisión mutante. Evoca Comunicación e Imagen, 5-9.

\section{- Sobre la autora:}

Carolina Soria es Doctora en Historia y Teoría de las Artes (Universidad de Buenos Aires), Investigadora Asistente de CONICET y Jefa de Trabajos Prácticos en la Cátedra "Historia del Cine Universal" (UBA).

\section{- ¿Cómo citar?}

Soria, C. (2020). Ficciones televisivas argentinas en los festivales internacionales de cine. Comunicación y Medios, (41), 117-128. doi: 10.5354/0719-1529.2020.56658 